\title{
Recent Advances in Arctic Cloud and Climate Research
}

\author{
Jennifer E. Kay ${ }^{1}$ - Tristan L'Ecuyer ${ }^{2} \cdot$ Helene Chepfer ${ }^{3}$ - Norman Loeb ${ }^{4}$. \\ Ariel Morrison $^{1} \cdot$ Gregory Cesana $^{5}$
}

Published online: 8 October 2016

(C) Springer International Publishing AG 2016

\begin{abstract}
While the representation of clouds in climate models has become more sophisticated over the last $30+$ years, the vertical and seasonal fingerprints of Arctic greenhouse warming have not changed. Are the models right? Observations in recent decades show the same fingerprints: surface amplified warming especially in late fall and winter. Recent observations show no summer cloud response to Arctic sea ice loss but increased cloud cover and a deepening atmospheric boundary layer in fall. Taken together, clouds appear to not affect the fingerprints of Arctic warming. Yet, the magnitude of warming depends strongly on the representation of clouds. Can we check the models? Having observations alone does not enable robust model evaluation and model improvement. Comparing models and observations is hard enough, but to improve models, one must both understand why models and observations differ and fix the parameterizations. It is all a tall order, but recent progress is summarized here.
\end{abstract}

Keywords Arctic $\cdot$ Clouds $\cdot$ Climate $\cdot$ Sea ice $\cdot$ Ice sheets

This article is part of the Topical Collection on Climate Feedbacks

Jennifer E. Kay

jennifer.e.kay@colorado.edu

1 Department of Atmospheric and Oceanic Sciences and Cooperative Institute for Research in Environmental Sciences (CIRES), University of Colorado-Boulder, Boulder, CO, USA

2 Department of Atmospheric and Oceanic Sciences, University of Wisconsin-Madison, Madison, WI, USA

3 LMD/IPSL, Univ. Pierre and Marie Curie, Paris, France

4 NASA Langley, Langley, VA, USA

5 NASA Jet Propulsion Laboratory, California Institute of Technology, Pasadena, CA, USA

\section{Introduction}

Climate change in the Arctic is a visible reality, with Arctic sea ice [1] and the Greenland ice sheet [2] melting. The goal of this review is to highlight recent advances in Arctic cloud and climate research from both observations and modeling perspectives. Two guiding questions are addressed: What are important recent advances in scientific understanding of Arctic clouds in a warming world? and What tools have made these advances in cloud-climate research possible and could lead to future advances? This review builds on a recent comprehensive review paper on Arctic cloud processes and resilience [3] and on a pioneering Arctic cloud-climate review paper [4]. Wherever possible, emphasis will be placed on how the tools for understanding Arctic cloud-climate processes have changed since the early days of climate modeling [5] and satellite observations [6].

\section{Why Are Clouds Important to Arctic Climate?}

By the late twenty-first century, greenhouse gas emissions dominate over internal variability and model physics as the primary source of uncertainty in future climate projections [7]. But, within a given emissions scenario - clouds exert control on future Arctic climate trajectories in two ways. First, on a global scale, cloud feedbacks and cloud-aerosol interactions dominate climate model uncertainty in global warming drivers [8]. Arctic sea ice loss and global mean temperature are positively correlated on climate timescales [9]. In other words, more global warming implies more Arctic sea ice loss. Therefore, processes controlling global warming drivers also control Arctic warming and ice melt. Second, on a local scale, Arctic clouds exert a strong influence on Arctic climate feedbacks. Both Winton [10] and Meehl et al. [11] traced model uncertainty in Arctic warming and sea ice loss trajectories to 
disparate representations of shortwave Arctic feedbacks including clouds. Cloud influence on Arctic climate goes beyond just cloud feedbacks because clouds regulate the strength of other Arctic feedbacks. For example, positive shortwave surface albedo feedbacks are larger in magnitude when clouds are optically thin than when clouds are optically thick [e.g., 12]. Beyond radiative feedbacks, clouds produce precipitation, which strongly influences the Arctic climate state (e.g., insulating and albedo impacts of snow on sea ice [13•]). No doubt, the influence of clouds on Arctic climate is multi-faceted.

Unfortunately, today's climate models do not agree on the answer to a basic Arctic cloud and climate question: What is the net cloud feedback in the Arctic in response to anthropogenic forcing? To illustrate this point, we describe two studies that use simulations from the last Coupled Model Intercomparison Project (CMIP5 [14]) to assess Arctic climate feedbacks in a multi-model framework. The first study, Zelinka et al. [15], reports a negative Arctic cloud feedback in CMIP5 over the Arctic Ocean (their Fig. 9) due to increased cloud optical depth, not increased cloud amount (their Fig. 8). Using different methods, a second study, Pithan et al. [16•], found that the CMIP5 mean Arctic cloud feedback is slightly positive but that the individual models do not agree on the sign of the Arctic cloud feedback (their Fig. 3). The disparate results from these two studies underline the difficulty to even diagnose cloud influence on Arctic climate in climate models and, in turn, the need for better constraints on Arctic clouds.

Interestingly, the sign of the Arctic cloud feedback is not a first-order control on the seasonal and vertical pattern of Arctic amplification. Indeed, multiple lines of evidence suggest the basic pattern of Arctic amplification is relatively insensitive to Arctic cloud feedbacks. For example, early climate models did not allow for cloud feedbacks because they prescribed clouds using observations, e.g., as zonal monthly means in Manabe and Stoeffer [5]. In contrast, today's climate models include cloud feedbacks because cloud formation and evolution are predicted based on dynamic interaction with the fully coupled climate system. Yet, despite this difference in cloud feedback inclusion, the seasonal and regional warming pattern response to increased greenhouse gases in climate models today (e.g., as summarized in [18]) matches models used in the early days of coupled climate modeling (e.g., Manabe and Stoeffer [5]). Also of importance, the longmodeled pattern of amplified lower-tropospheric warming especially in fall and winter is in agreement with recent observations [19, 20]. Consistent with the notion that clouds do not explain Arctic amplification patterns, Pithan et al. [16•] found that lapse rate feedbacks and surface albedo feedbacks explain the basic pattern of Arctic amplification in CMIP5. Also relevant, Kay et al. [12] and Pithan et al. [16•] both found that local feedbacks, not advective feedbacks, explain Arctic surface warming in response to increased greenhouse gases.
Even though the basic pattern of Arctic greenhouse warming appears relatively insensitive to clouds, it remains important to understand cloud processes and to constrain cloud influence on Arctic warming magnitude. This review highlights recent advances in Arctic cloud-climate research and is organized as follows: We start by describing how and why new observations are revolutionizing our understanding of Arctic cloud-climate processes. We then discuss that the best path forward for improved understanding of Arctic clouds and their role in the climate system is a two-way street between models and observations. We conclude by looking forward towards new opportunities in Arctic cloud and climate science.

\section{Observational Advances for Arctic Clouds over the Last Decade}

A well-regarded geologist professed that scientific discoveries occur when one can "associate oneself with new observations of what appear to be prominent yet unexplored or poorly understood features of Earth" [21]. We agree with this assessment, and build on it here. We propose a simple equation to predict scientific discovery: dramatic change + new observations $=$ new discoveries. The record-setting Arctic sea ice loss and Greenland melting certainly provide dramatic change, especially over the last decade with many new records being set-but what are the new observations that have fueled discovery? We argue new satellite observations from the A-train, and in particular, the spaceborne radar CloudSat [22] and lidar platform Cloud-Aerosol Lidar and Infrared Pathfinder Satellite Observation (CALIPSO) [23] have completely transformed Arctic cloud-climate studies. The A-train satellite constellation [24] enables investigation with multiple coincident measurements and therefore lends itself to process understanding. Collocation of A-train measurements with ancillary data from reanalysis is beginning [25]. A-train observations complement field campaigns and long single-point time series at ground-based "supersites" in the Arctic. The longest supersite record is from Barrow, Alaska as a part of the Atmospheric Radiation Measurement program [26, 27], but supersites in Eureka [28] and Summit, Greenland [29] are also important sources of new cloud and radiation observations. These supersites, when combined with airborne and shipborne observations from individual field campaigns, have provided invaluable insights into Arctic cloud processes and have helped test theory as summarized in [3]. A-train observations, especially those from CloudSat and CALIPSO, provide spatio-temporal context for the process understanding gained from supersites and field campaigns. This spatio-temporal context is especially important given the dearth of observations over the increasingly ice-free Arctic Ocean and the melting Greenland ice sheet. For many years, new discoveries emerged from the analysis of ground-based, ship-based, and 
airborne observations but the past decade ushered in a new era of satellite observations that we argue here have transformed Arctic cloud-climate studies.

Many new observations are available so why are the nearly 10 years of active satellite observations from CloudSat and CALIPSO especially transformative for Arctic cloud-climate research? CloudSat and CALIPSO have three unique advantages in polar regions. First, they are active sensors that observe cloud vertical structure. Polar clouds are geometrically and optically thinner than their lower latitude cousins, enabling CloudSat and CALIPSO to pass through the atmosphere with less attenuation and return usable signals close to the surface. As a result, vertical hydrometeor structure is observed by CloudSat and CALIPSO in polar regions and with much deeper penetration through the atmosphere than at lower latitudes. Second, polar cloud phase is not well known, and the processes underlying phase transitions in current and warming climate are hard to observe and predict from first principles. Thus, CALIPSO cloud phase observations are especially important in polar regions [30] and have been vetted against in situ airborne measurements [31]. Third, polar hydrometeors cover surfaces with highly variable albedos and albedos that are changing in a warming world (e.g., as a consequence of sea ice loss). CloudSat and CALIPSO are "surface-blind" when it comes to albedo and do not suffer from the same passive instrument retrieval challenges over bright and cold surfaces. Given these three unique observational advantages and the global climate importance of polar regions in a warming climate-CloudSat and CALIPSO are advancing our understanding of polar clouds and precipitation processes and their impact on the global climate system. There is no doubt that CloudSat and CALIPSO, in concert with other satellite and ground-based observations, have advanced understanding and modeling of polar cloud and precipitation processes in a warming world. Affiliated discoveries are many, but we highlight three discoveries here.

\section{Discovery no. 1: Importance of Liquid-Containing Clouds for Arctic Climate}

Discovery no. 1 is the first-order importance of supercooled liquid clouds for surface radiative fluxes over the Arctic Ocean [30] and over Greenland [32••]. To illustrate this discovery, Fig. 1 shows the distribution of liquid-containing clouds over the Arctic from nearly a decade of CALIPSO observations. Liquid-containing clouds are present in all seasons and in all locations. Using a year of ground-based observations, Shupe and Intrieri [33] were the first to report the frequent occurrence of and importance of liquid clouds for Arctic radiation budgets (their Fig. 4). Before CALIPSO observations, we had no way to know if the single-year singledrifting-point results of Shupe and Intrieri [33] were representative of the entire Arctic. Similarly, Bennartz [34] first emphasized the importance of liquid-containing clouds and in particular, the sensitivity of the ice sheet melt to detailed cloud properties for Greenland melting. Miller et al. [35] quantified cloud radiative forcing at Summit, Greenland, and the importance of liquid clouds. But, it was the CALIPSO cloud phase observations that revealed the ubiquitous presence of this influential cloud type over the entire Arctic, including the Arctic Ocean and Greenland.

Beyond revealing the ubiquitous presence of liquidcontaining clouds, when combined with A-train and other complementary observations, radiative transfer calculations have been used to directly assess the influence of liquidcontaining and all clouds on radiation budgets (e.g., as was done for the Arctic Ocean [36] and for Greenland [32••]). Figure 2 shows the annual cycle of the cloud radiative effect (CRE) at the surface and the top-of-atmosphere (TOA) over the Arctic Ocean [37]. CRE is calculated as the difference between the all-sky and clear-sky fluxes. The CRE calculations show clouds cool the Arctic Ocean during summer but warm the Arctic Ocean during winter. Due to the large downwelling longwave radiation at the surface, longwave cloud heating is larger at the surface than at the TOA. As a result, there is a net cloud warming at the surface but a net cloud cooling at the TOA. Differencing the TOA and the surface CRE provides an estimate of cloud influence on the atmosphere. Taking this difference shows that Arctic clouds strongly cool the Arctic atmosphere by $22 \mathrm{Wm}^{-2}$, in contrast to the global mean where clouds warm the atmosphere by $2 \mathrm{Wm}^{-2}$.

\section{Discovery no. 2: Increased Absorbed Shortwave Radiation Associated with Sea Ice Loss During Summer}

Discovery no. 2 is the apparent lack of evidence for summer cloud feedback in response to Arctic sea ice loss. Building on the discovery of reduced cloud cover during the recordbreaking 2007 summer sea ice loss, Kay et al. [38] and Kay and Gettelman [39] found no evidence for summer cloud feedback in response to Arctic sea ice loss from analysis of 3-year A-train observations (2006-2008) (their Fig. 8; see also Kay and L'Ecuyer [36]; Fig. 8). Kay and Gettelman [39] explain this lack of a summer cloud response to summer sea ice loss using near-surface static stability and air-sea temperature gradients. Over the Arctic Ocean, temperature inversions and weak air-sea temperature gradients limit atmosphere-ocean coupling during summer ([39]; Fig. 5). The relatively high static stability and weak air-sea gradients during summer limit upward turbulent fluxes of moisture and heat. As a result, the summer boundary layer overlying the Arctic Ocean is unaffected by converting ice-covered ocean into ice-free ocean.

The lack of a summer cloud response to newly open water is consistent with large increase in absorbed shortwave radiation associated with sea ice loss $[36,41,42]$ in TOA radiation 


\section{(a) DJF Total}

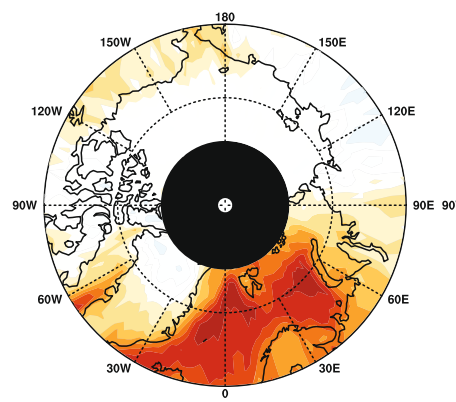

(e) DJF Liquid

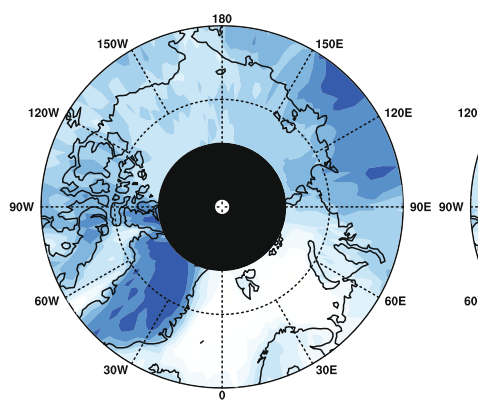

(b) MAM Total

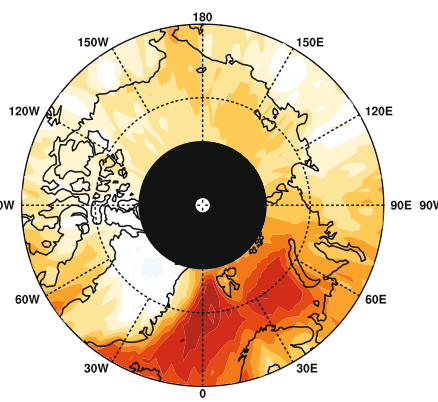

(f) MAM Liquid (c) JJA Total

(d) SON Total

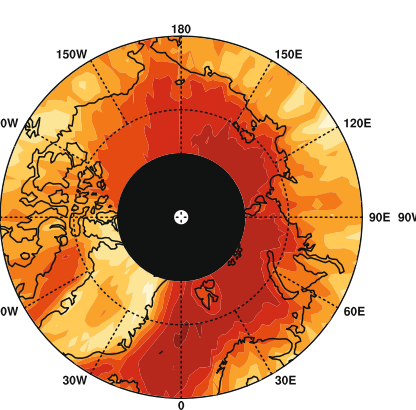

(g) JJA Liquid

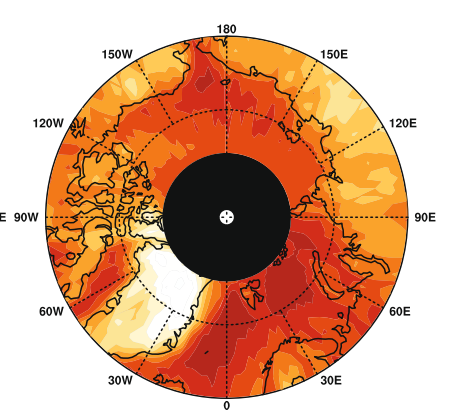

(h) SON Liquid

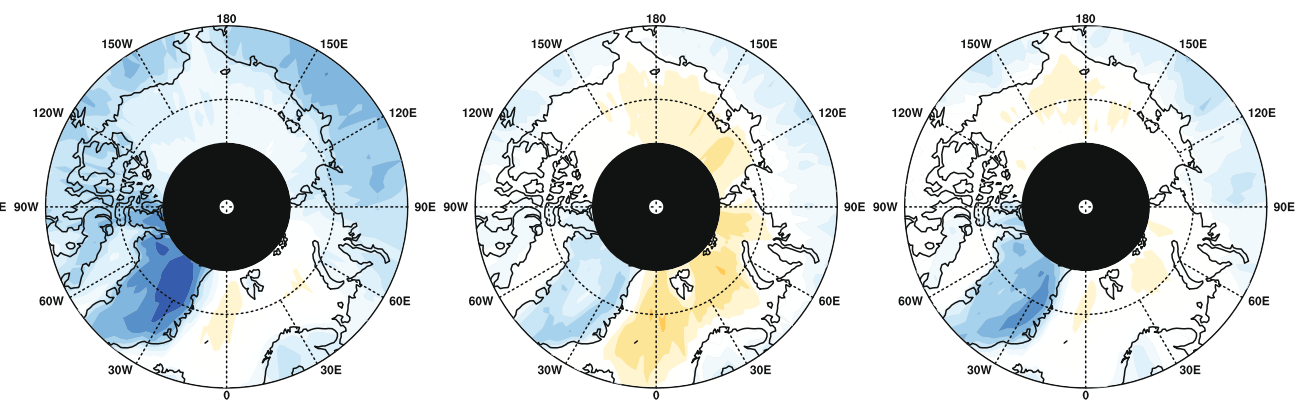

CALIPSO Clouשover (\%)

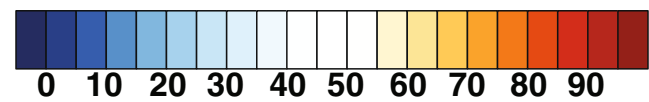

Fig. 1 CALIPSO-GOCCP cloud cover observations: a DJF total, b MAM total, c JJA total, d SON total, e DJF liquid-containing, f MAM liquid-containing, g JJA liquid-containing, and $\mathbf{h} \mathrm{SON}$ liquid containing.

measurements from Clouds and Earth's Radiant Energy System (CERES) satellite [17]. To illustrate this result, Fig. 3 contains maps of solar radiation gains and sea ice loss over the period 2000 to 2015. The largest sea ice loss regions have the largest absorbed shortwave radiation increases. In a warming Arctic during summer and peak incoming solar insolation, one bright surface (disappearing sea ice) is not being replaced with another bright surface (clouds). The combination of TOA radiative flux observations from CERES with surface-blind cloud observations from CloudSat and CALIPSO is powerful for quantifying the absence of a summer shortwave cloud feedback in response to sea ice loss.

\section{Discovery no. 3: Fall Clouds Respond to Arctic Sea Ice Loss}

Discovery no. 3 is the increased fall cloud cover and boundary layer deepening in response to Arctic sea ice loss [39, 43-45]. In contrast to summer, Kay and Gettelman [39] found that turbulent transfer of heat and moisture promotes low cloud formation over newly open water during fall. Arctic boundary layer also deepened over newly open water in fall. The relatively low static stability and strong air-sea gradients during
Observations are from June 2006 to December 2015 using CALIPSOGOCCP version 2.9. Figure updated from Cesana et al. [30], who plotted data from June 2006 to December 2011

fall permit upward turbulent fluxes of moisture and heat and additional low cloud formation over newly open water. The study period was short (3 years), and a climatological assessment of observational constraints on cloud-sea ice feedbacks is desperately needed. Nevertheless, this study underscores the importance of understanding physical processes before analyzing trends and averaging geographically and/or seasonally.

Because of their seasonal timing, discovery nos. 2 and 3 suggest cloud changes resulting from sea ice loss play a minor role in regulating ice-albedo feedbacks at its peak during summer but may contribute to a cloud-ice feedback in fall. Schweiger et al. [46] note that any fall cloud feedback might not be very influential because of the compensating shortwave cooling and longwave warming impacts of clouds. In summary, summer and fall Arctic cloud changes resulting from sea ice loss most likely have a relatively small influence on surface energy budget and sea ice changes, but more analysis and observations are needed to directly measure physical mechanisms and quantify cloud-sea ice interactions in all seasons. For example, increased cloud cover in winter only influences longwave radiation and therefore should lead to positive longwave cloud-sea ice feedbacks. 


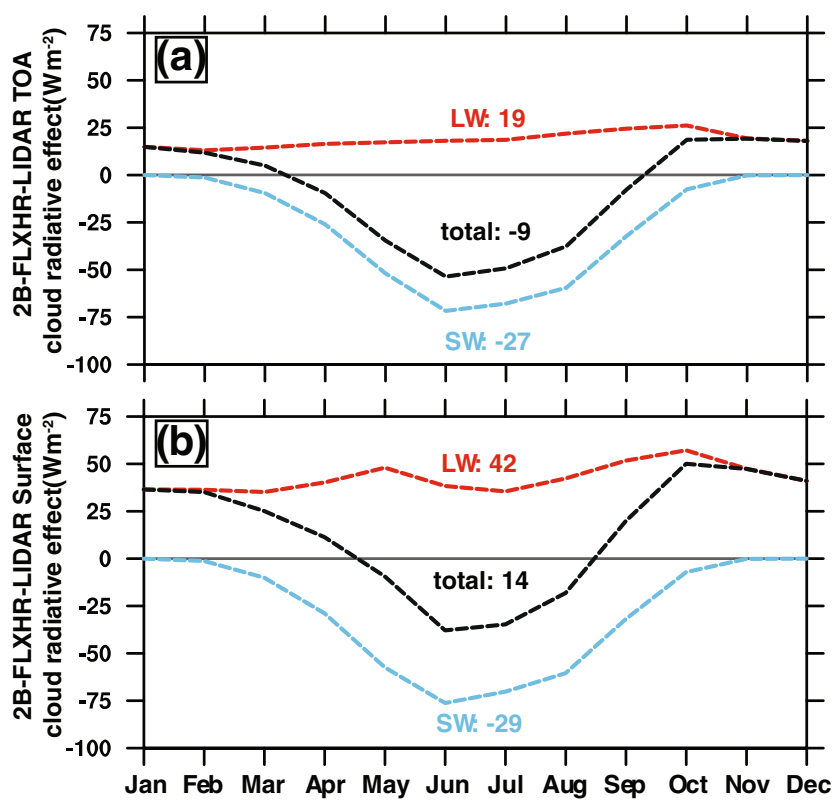

Fig. 2 Seasonal cycle of cloud radiative effect (CRE) over the seasonally ice-covered ocean: a top-of-the-atmosphere and $\mathbf{b}$ surface. CRE from the latest version (R05) of the CloudSat fluxes and heating rates product [37]. Figure updated from Kay and L'Ecuyer [36], who used the R04 version of the CloudSat fluxes and heating rates product

\section{Despite Advances-Observational Challenges Remain}

Despite the discoveries enabled by recent new observations, many observational challenges remain. One major challenge is that Arctic cloud feedbacks resulting from Arctic cloud changes alone are hard to isolate. There are large non-cloud influences on CRE, the most common measure of cloud in- fluence on climate (Fig. 2). Non-cloud influences on CRE include surface albedo [47] and water vapor [48]. It is well known that surface albedo has a dominant influence on wheth- er clouds warm or cool the surface as measured using CRE. As a result, a change in surface albedo can change the CRE sign even if there are no changes in the cloud properties themselves. For example, when Arctic Ocean becomes ice-free, the shortwave cooling effect of clouds as measured by CRE increases due to the reduced surface albedo. While methods exist to separate non-cloud influence on CRE in models (e.g., [49-51]), reliably using these methods with Arctic observations remains challenging.

Another challenge is that while TOA radiative fluxes are more easily observed and incorporated into feedback frameworks, the TOA perspective does not tell the whole story. Arctic sea ice and land ice respond to the surface energy budget, which differs from the TOA radiative fluxes. Why? First, unlike at the TOA, scattering between the clouds and the surface influences the downwelling shortwave radiation at the surface. In a warmer world with more open water and less sea ice, there is less multiple scattering between the bright clouds and the surface. As a result, there is less downwelling shortwave radiation in a warmer world with less sea ice (e.g.,
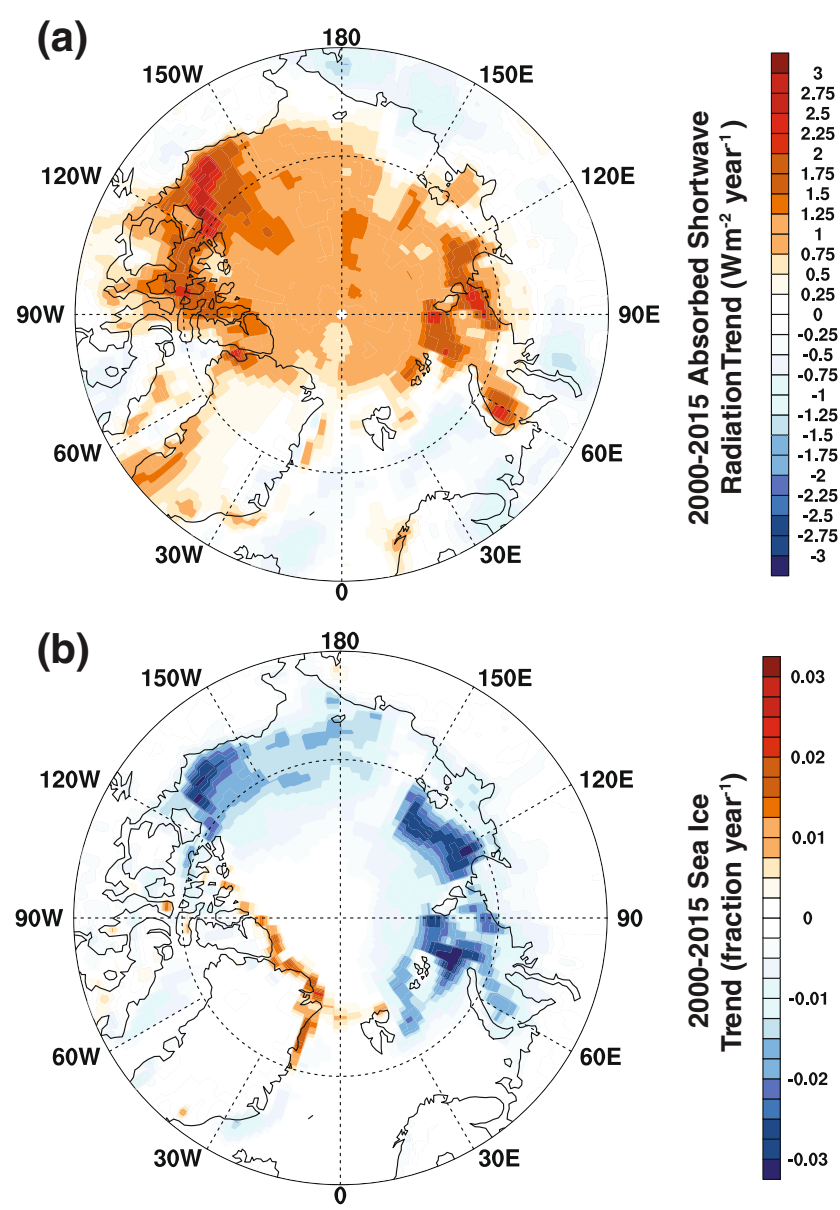

Fig. 3 Arctic maps of observed summer (JJA) 2000-2015 trends: a topof-atmosphere absorbed shortwave radiation from CERES-EBAF [17] and $\mathbf{b}$ sea ice fraction from SSF1deg edition 3 dataset

DeWeaver et al. [52], Frikken and Hazeleger [53]). Importantly, because these downwelling shortwave radiation reductions are driven by surface albedo reductions, they occur even if the clouds remain identical (i.e., if there is no cloud response to summer sea ice loss as suggested by discovery no. 2 above). Second, unlike at the TOA, increased low cloud cover has a large influence on downwelling surface longwave radiation. Consequently, the increased fall boundary layer cloud cover over open water associated with sea ice loss (discovery no. 3 above) may have a small impact on TOA longwave radiation but may also lead to large increases in surface downwelling longwave radiation.

Unfortunately, direct observations of surface radiation over the Arctic Ocean remain few and far between. Therefore, the best path forward to quantify the influence of clouds on surface radiative fluxes is observationally constrained radiative transfer calculations [e.g., 37, 54]. Though these calculations are strongly guided by in situ and remote sensing observations, many assumptions must be made to calculate fluxes. Constraining radiative transfer calculations over the Arctic is challenging with the limited cloud and atmospheric temperature and humidity profiles that are available. One particular 
Table 1 Spring (MAM) Arctic $\left(70-90^{\circ} \mathrm{N}\right)$ average values for 2006-2025 in two fully coupled climate models (model no. $1=$ CCSM4, model no. 2 = CESM1CAM5)

\begin{tabular}{llll}
\hline & Model no. 1 & Model no. 2 & Difference \\
\hline Low cloud cover $(\%)$ & $38 \%$ & $73 \%$ & $-35 \%$ \\
Total grid-box liquid water path $\left(\mathrm{gm}^{-2}\right)$ & 87 & 7 & 80 \\
Downwelling shortwave at the surface $\left(\mathrm{Wm}^{-2}\right)$ & 148 & 163 & -15 \\
Surface albedo (ratio) & 0.58 & 0.74 & -0.16 \\
Net shortwave at the surface $\left(\mathrm{Wm}^{-2}\right)$ & 38 & 39 & -1 \\
Downwelling longwave at the surface $\left(\mathrm{Wm}^{-2}\right)$ & 205 & 196 & 8 \\
Sea ice fraction (fraction) & 0.62 & 0.62 & -0.01 \\
\hline
\end{tabular}

challenge is measuring cloud liquid water path, which is known to have a large influence on surface radiative fluxes [34, 36, 55]. At present, no spaceborne satellite is able to directly measure liquid water path in polar regions. CALIPSO provides useful observations related to liquid water path including the occurrence frequency of opaque clouds and cloud phase. CloudSat measures radar reflectivity, but estimating liquid water path based on radar reflectivity requires estimating two unknowns (drop size, drop number) with one measurement (radar reflectivity). Passive microwave is the best available constraint on total column cloud liquid water path, but satellite microwave retrievals do not work over ice-covered surfaces [56].

\section{Going Forward on a Two-Way Street: Models Informing Observations}

We believe that the best path forward is a two-way street between models and observations. To some, it may be counterintuitive to start our two-way street discussion with models, but even flawed models teach us a lot about observational priorities. What have we learned from climate models that is useful for observing?

First, models show us that clouds are a first-order control on the evolution of the fully coupled climate system. While one might argue that you can learn this lesson from observations alone, we argue that you need a model to understand the sensitivity of the fully coupled climate system to clouds. Here, we provide examples from a global fully coupled climate model - the Community Earth System Model (CESM) [57] - to show that clouds do exert important controls on simulated Arctic climate.

The first example is basic. In the most recent version of CESM (CESM1-CAM5), Kay et al. [58] found that Greenland was too cold because of insufficient liquid containing clouds (their Fig. 7). No doubt that it is difficult to use a climate model to project Greenland melting if it is too cold in its present state.

The second example relates to Arctic sea ice and model tuning. The Arctic sea ice edge is maintained by two primary factors: absorbed solar radiation and the convergence of heat transported by ocean currents [59]. Clouds are a first-order control on absorbed shortwave radiation and thus have the potential to impact the sea ice edge and thickness. We illustrate the influence of clouds, particularly liquid clouds, on Arctic sea ice simulations by comparing two CESM versions that differ only in their atmospheric model components: the Community Climate System Model version 4 (CCSM4) and CESM1-CAM5. While the cloud fraction in CESM1-CAM5 is double that in CCSM4, the clouds in CCSM4 have a lot more cloud liquid water content than the clouds in CESM1-CAM5 (Table 1; Fig. 4). Underscoring the importance of looking at more than just cloud fraction, the model with higher cloud fraction (CESM1-CAM5) has more downwelling shortwave and less downwelling longwave than the model with more liquid in the clouds (CCSM4). The adjustment of surface albedos within observational uncertainty to compensate for solar radiation differences is often necessary to achieve a credible Arctic sea ice mean thickness. As discussed by DeWeaver et al. [52] and is evident by comparing the cloud fraction differences in Table 1, albedo adjustment is not as simple as regressing cloud fraction and absorbed shortwave radiation. Figure 4 shows that the downwelling shortwave differences between the two models are compensated by surface albedo differences. As a result, the net shortwave radiation in the two models is within $1 \mathrm{Wm}^{-2}$ and the sea ice fraction is within 0.01 (Table 1). Because CALIPSO observes liquid-containing cloud (Fig. 1), CALIPSO provides a powerful observational constraint on Arctic clouds in climate models. For example, CESM1-CAM5 has too few Arctic liquid clouds ([58], their Fig. 4) suggesting that the high surface albedo values used in CESM-CAM5 may be compensating for insufficient liquid cloud and insufficient cloud opacity.

Second, large unpredictable variability in climate simulated by fully coupled climate models teaches us to be humble about interpreting short observational records. Physically based models are flawed, but they also provide invaluable framework (a "grille de lecture") to refine observational interpretations, to test hypotheses, and to quantify the influence of clouds within the fully coupled climate system. Correlations and trends happen but that 
(a) MODEL \#1

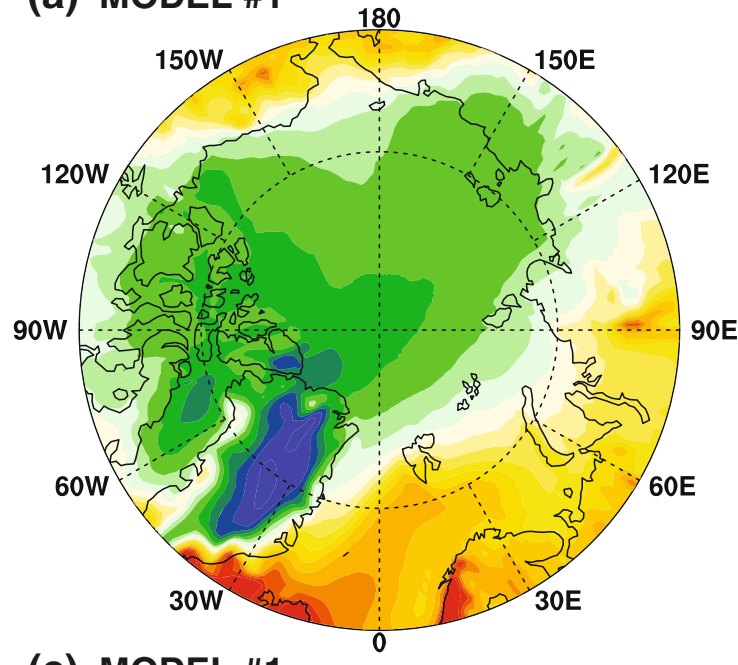

(c) MODEL \#1

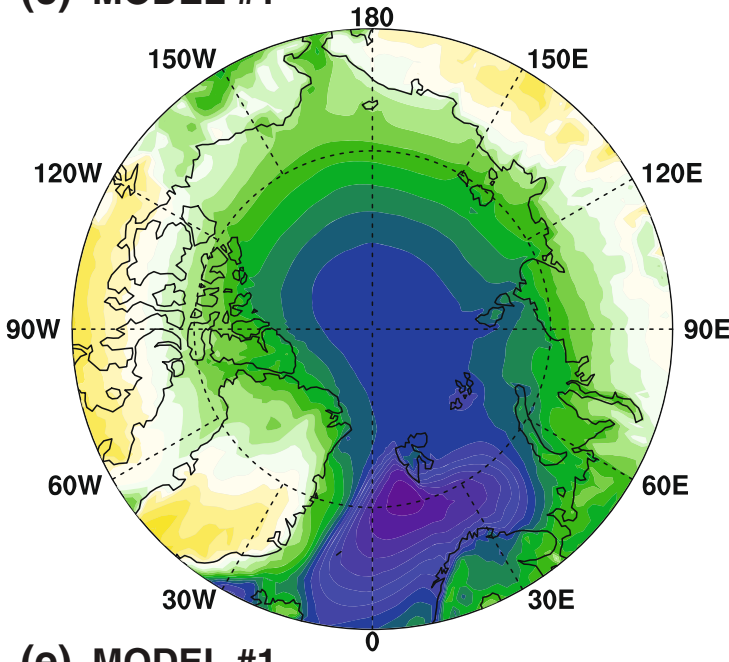

(e) MODEL \#1

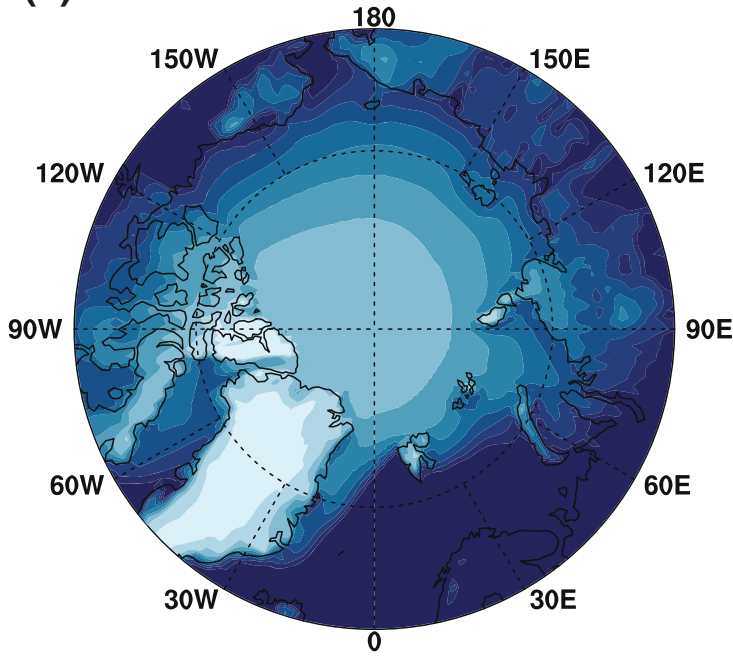

(b) MODEL \#2

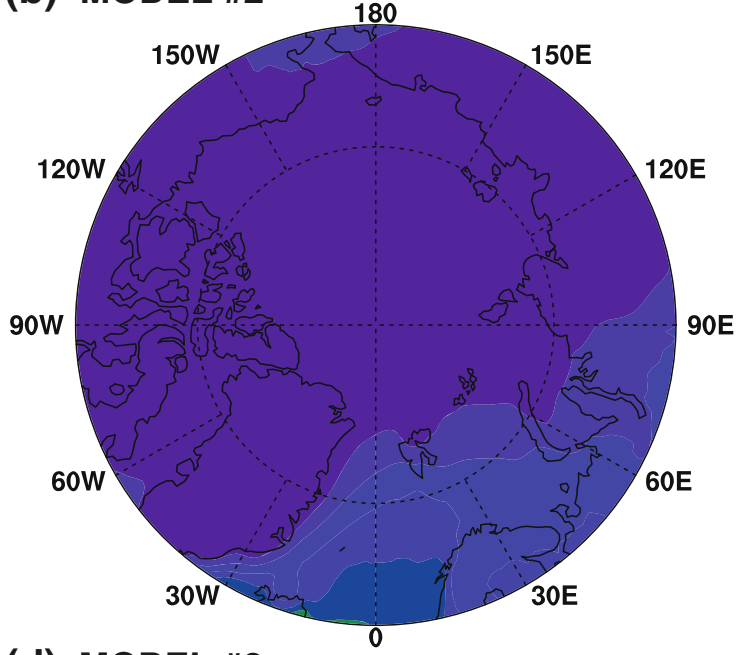

(d) MODEL \#2
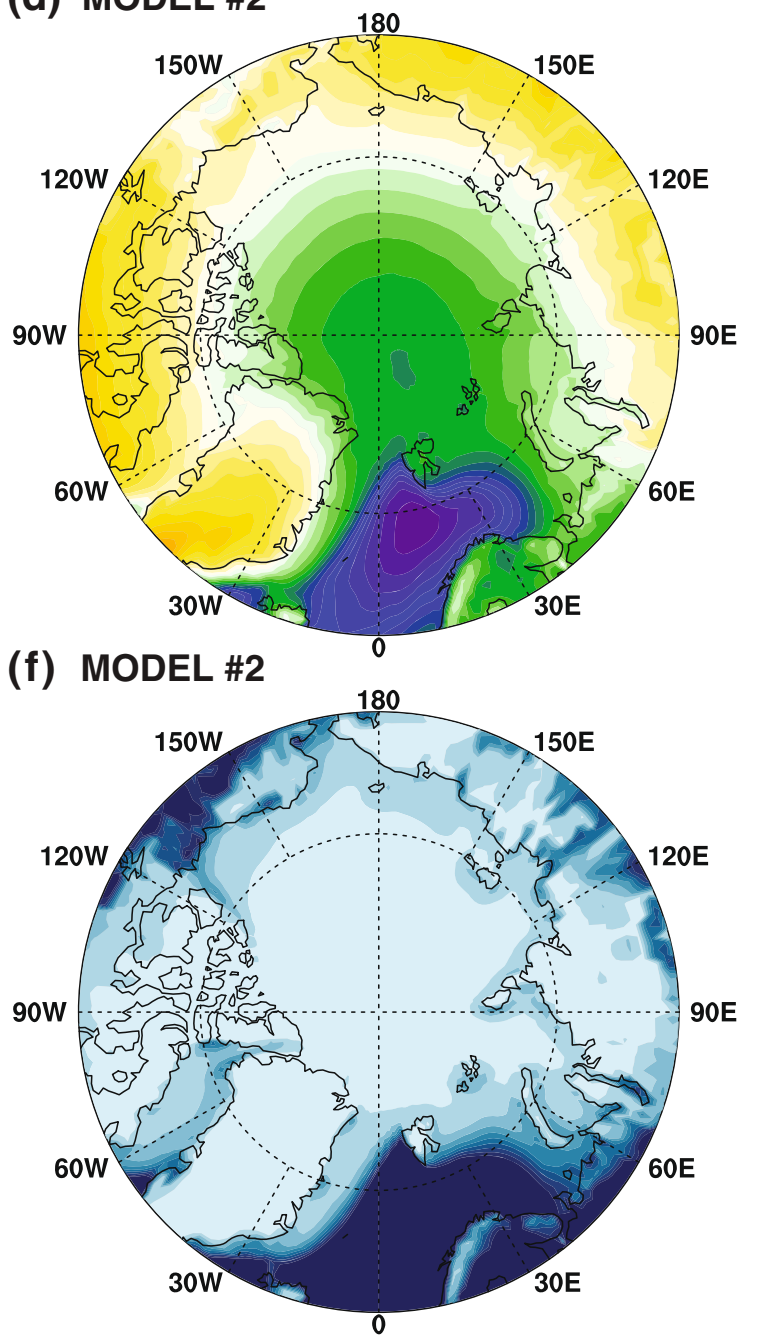

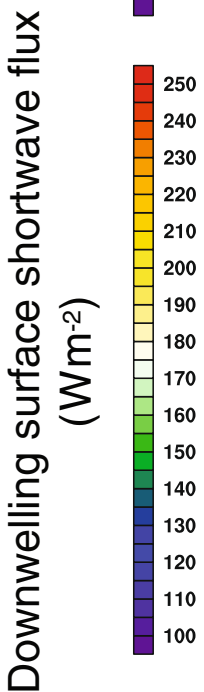
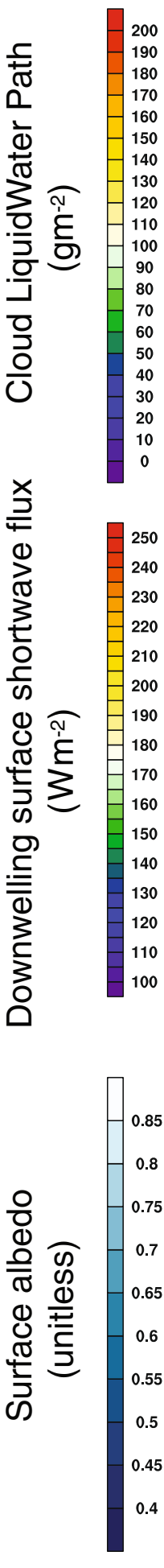

Fig. 4 Spring (MAM) 2006-2025 Arctic maps in two climate models: a, b total grid-box cloud liquid water path (LWP); c, d downwelling shortwave flux at surface in CCSM4; and e, $\mathbf{f}$ surface albedo. Model no. 1 is CCSM4, model no. 2 is CESM1-CAM5

does not mean they are causal, as discussed in Caldwell et al. [60]. Climate models simulate large internal variability on sub-decadal timescales (e.g., $[61 \bullet, 62])$, and the existence of large internal variability elevates the need for physical mechanisms when identifying correlations and trends as causal. 


\section{Going Forward on a Two-Way Street: Observations Informing Models}

What have we learned from observations that is useful for modeling? Observations are critical for informing models, but it is not always easy to go from observational advances to model improvements. We offer some insights here for how observations can best inform model development and improvement.

We start with a simple important rule that is obvious, yet frequently ignored. Observations best inform models when observations and models can be consistently compared. Yet, making robust comparisons between models and observations is actually really hard to do. In fact, with the exception of the most basic integrated quantities, directly comparing climate model output to observations can be highly misleading. Why? Geophysical parameters in climate models and observations are not the same due to a number of fundamental differences between the modeled and retrieved quantities, including finite observational detection thresholds, differences in sampling, scale, and even the physical representation of the relevant processes.

For clouds, recent work has shown the immense value of simulators to make scale-aware and definition-aware comparisons between observations and models (e.g., [40, 58, 63-66]). Figure 5 shows an example of the value of the CALIPSO simulator [63] when evaluating Arctic clouds in the Community Atmosphere Model version 5 (CAM5) [67]. If one were to naively compare the model cloud fraction (labeled "CAM5") to CALIPSO observations (labeled "CALIPSO"), one would conclude that the model is very biased with twice as much winter cloud as the CALIPSO observations. If instead one makes fair and consistent "apple-to-apple" comparisons between the CALIPSO-simulated model cloud fraction (labeled "CAM5_CALIPSO") and the CALIPSO observations, the conclusion is shockingly different- the model bias

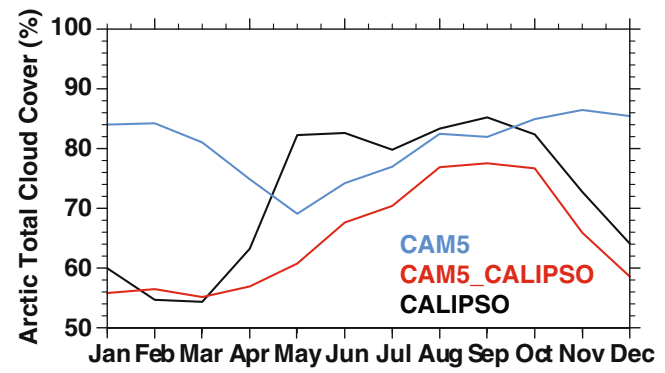

Fig. 5 Monthly mean Arctic cloud cover from CALIPSO-GOCCP observations ("CALIPSO," black), CAM5 model cloud with CALIPSO simulator ("CAM5 CALIPSO," red), and default CAM5 model cloud fraction ("CAM5," blue). CAM5 simulations are from Kay et al. [40] during winter is much smaller and the model seasonal cycle also better matches the observations. It is not surprising that the CAM5-produced cloud cover is more than the CALIPSO-simulated cloud cover. In the Arctic, CAM5 has optically thin clouds that the CALIPSOGCM-Oriented CALIPSO Cloud Product (CALIPSOGOCCP) [68] does not include. Making a fair comparison means using the same definition of clouds. In this example, CAM5_CALIPSO and CALIPSO can be compared because they both define cloud as an object detected by a spaceborne lidar that has a scattering ratio greater than 5 .

The "parameterization way of thinking" is the only way to improve models using observations. Changing the equations that are being used to represent physical processes is the only way to improve the model physics using observations. Sometimes, the reasons that climate models produce incorrect clouds are pathological. For example, parameterizations designed for lower latitudes are used globally without being tested at high latitudes. In this case, extending the physical process representation to make the assumptions appropriate for all regions can be a simple fix (e.g., [69]). Often, identifying ways to improve models using observations is really hard. To make progress, it is often advantageous to work with instantaneous correlations not the temporal mean (e.g., as has been done in $[70,71])$. Indeed, co-locating instantaneous data is a powerful tool for understanding parameterization flaws at a process level that should be more frequently exploited to connect observations with model development and improvement.

\section{Conclusions}

Advances in our understanding of Arctic clouds and climate have been fueled by the effective combination of observing and modeling tools. For the Arctic cloud and climate research, the nearly 10 years of satellite radar and lidar observations provided by CloudSat and CALIPSO has been especially transformative. The future is bright with many planned observations from more satellites with active remote sensing instruments (e.g., EarthCARE [72]) from new platforms such as unmanned UAVs [73] and from in situ field experiments (e.g., Multidisciplinary Drifting Observatory for the Study of Arctic Climate (MOSAIC) drifting ship field campaign 2018-2019). Continued work on the two-way street of making process-level connections between models and observations is essential, and thankfully, this work is blossoming into new research discoveries and advances in our understanding of Arctic clouds and climate. 


\section{Compliance with Ethical Standards}

Conflict of Interest There is no conflict of interest.

\section{References}

Papers of particular interest, published recently, have been highlighted as:

- Of importance

•- Of major importance

1. Stroeve JC, Serreze MC, Holland MM, Kay JE, Meier W, Barrett AP. The Arctic's rapidly shrinking sea ice cover: a research synthesis. Clim Chang. 2011. doi:10.1007/s10584-011-0101-1.

2. Shepherd A et al. A reconciled estimate of ice sheet mass balance. Science. 2012;338:1183-9. doi:10.1126/science.1228102.

3. Morrison H, de Boer G, Feingold G, Harrington JY, Shupe MD, Sulia K. Resilience of persistent Arctic mixed-phase clouds. Nat Geosci. 2012;5:11-7. doi:10.1038/ngeo1332.

4. Curry JA, Rossow WB, Randall D, Schramm JL. Overview of arctic cloud and radiation characteristics. J Clim. 1996;9:1731-64.

5. Manabe S, Stouffer RJ. Sensitivity of a global climate model to an increase of $\mathrm{CO} 2$ concentration in the atmosphere. J Geophys Res. 1980;85(C10):5529-54.

6. Ramanathan, V., R. D. Cess, E. F. Harrison, P. Minnis, B. R. Barkstrom, E. Ahmad, and D. Hartmann Radiative forcing and climate: results from the earth radiation budget experiment. Science. 1989;243(4887). doi:10.1126/science.243.4887.57.

7. Hawkins E, Sutton R. The potential to narrow uncertainty in regional climate predictions. Bull. Amer. Meteor. Soc. 2009;90:1095107. doi:10.1175/2009BAMS2607.1.

8. Boucher O, Randall DD, Artaxo P, Bretherton C, Feingold G, Forster P, Kerminen V-M, Kondo Y, Liao H, Lohmann U, Rasch P, Satheesh SK, Sherwood S, Stevens B, Zhang XY. Clouds and aerosols. In: Stocker TF, Qin D, Plattner G-K, Tignor M, Allen SK, Boschung J, Nauels A, Xia Y, Bex V, Midgley PM, editors. Climate change 2013: the physical science basis. Contribution of Working Group I to the Fifth Assessment Report of the Intergovernmental Panel on Climate Change. Cambridge, United Kingdom and New York, NY, USA: Cambridge University Press; 2013.

9. Winton, M. Do climate models underestimate the sensitivity of Northern Hemisphere sea ice cover? J Clim. 2011;24(15). doi:10.1175/2011 JCLI4146.1.

10. Winton M. Amplified Arctic climate change: what does surface albedo feedback have to do with it? Geophys Res Lett. 2006;33: L03701. doi:10.1029/2005GL025244.

11. Meehl G, Washington WM, Arblaster JM, Hu A, Teng H, Kay JE, Gettelman A, Lawrence DM, Sanderson BM, Strand WG. Climate change projections in CESM1(CAM5) compared to CCSM4. J Clim. 2013. doi:10.1175/JCLI-D-12-00572.1.

12. Kay JE, Holland MM, Bitz C, Blanchard-Wrigglesworth E, Gettelman A, Conley A, Bailey D. The influence of local feedbacks and northward heat transport on the equilibrium Arctic climate response to increased greenhouse gas forcing in coupled climate models. J Clim. 2012a;25: 5433-50. doi:10.1175/JCLI-D-11-00622.1.

13. Blanchard-Wrigglesworth E, Farrell S, Newman, T, and Bitz, C. M., (2015) Snow cover on Arctic sea ice in observations and an earth system model. Geophys Res Lett. 42. doi:10.1002/2015GL066049. This paper describes the influence of snow on sea ice within a fully coupled climate model.

14. Taylor KE, Stouffer RJ, Meehl GA. An overview of CMIP5 and the experiment design. Bull. Amer. Meteor. Soc. 2012;93:485-98.
15. Zelinka MD, Klein SA, Taylor KE, Andrews T, Webb MJ, Gregory JM, Forster PM. Contributions of different cloud types to feedbacks and rapid adjustments in CMIP5. J Clim. 2013;26:5007-27. doi:10.1175/JCLI-D-12-00555.1.

16. Pithan F, Mauritsen T. Arctic amplification dominated by temperature feedbacks in contemporary climate models. Nat Geosci. 2014;7:181-4. doi:10.1038/ngeo2071. This paper quantifies influence of local and advective feedbacks on Arctic warming in current climate models.

17. Loeb NG, Wielicki BA, Doelling DR, Smith GL, Keyes DF, Kato S, Manalo-Smith N, Wong T. Toward optimal closure of the Earth's top-of-atmosphere radiation budget. J Clim. 2009;22:748-66. doi:10.1175/2008JCLI2637.1.

18. Collins M, Knutti R, Arblaster J, Dufresne J-L, Fichefet T, Friedlingstein P, Gao X, Gutowski WJ, Johns T, Krinner G, Shongwe M, Tebaldi C, Weaver AJ, Wehner M. Long-term climate change: projections, commitments and irreversibility. In: Stocker TF, Qin D, Plattner G-K, Tignor M, Allen SK, Boschung J, Nauels A, Xia Y, Bex V, Midgley PM, editors. Climate change 2013: the physical science basis. Contribution of Working Group I to the Fifth Assessment Report of the Intergovernmental Panel on Climate Change. Cambridge, United Kingdom and New York, NY, USA: Cambridge University Press; 2013.

19. Serreze MA et al. The emergence of surface-based Arctic amplification. Cryosphere. 2009;3:11-9.

20. Screen JA, Simmonds I. The central role of diminishing sea ice in Arctic temperature amplification. Nature. 2010;464:1334-7.

21. Oliver, J. E. The Incomplete guide to the art of discovery. Columbia Univ. Press; 1991. 208 pp.

22. Stephens GL et al. CloudSat mission: performance and early science after the first year of operation. J Geophys Res. 2008;113: D00A18. doi:10.1029/2008JD009982.

23. Winker DM, Vaughan MA, Omar AH, Hu Y, Powell KA, Liu Z, Hunt WH, Young SA. Overview of the CALIPSO mission and CALIOP data processing algorithms. J Atmos Ocean Technol. 2009;26:2310-23. doi:10.1175/2009JTECHA1281.1.

24. L'Ecuyer TS, Jiang J. Touring the atmosphere aboard the A-train. Phys Today. 2010;63:36-41.

25. Christensen MW, Behrangi A, L'Ecuyer T, Wood NB, Lebsock MD, Stephens GL. Arctic observation and reanalysis integrated system: a new data product for validation and climate study. Bull. Amer. Meteor. Soc. 2016. doi:10.1175/BAMS-D-14-00273.1.

26. Verlinde, J., B.D. Zak, M.D. Shupe, M.D. Ivey, and K. Stamnes, 2016: The ARM North Slope of Alaska (NSA) sites. The atmospheric radiation measurement program: first 20 years, Meteor. Monogr. In: Ackerman TP, Stokes G, Wiscombe W, Turner D, editors. Am Meteor Soc. doi:10.1175/AMSMONOGRAPHS-D-15-0023.1.

27. Dong, X., et al. 2010, A 10 year climatology of Arctic cloud fraction and radiative forcing at Barrow, Alaska. doi:10.1029/2009 JD013489.

28. de Boer G, Eloranta EW, Shupe MD. Arctic mixed-phase stratus properties from multiple years of surface-based measurements at two high-latitude locations. J Atmos Sci. 2009;66:2874-87.

29. Shupe MD, Turner DD, Walden VP, Bennartz R, Cadeddu M, Castellani B, Cox C, Hudak D, Kulie M, Miller N, Neely III RR, Neff W, Rowe P. High and dry: new observations of tropospheric and cloud properties above the Greenland ice sheet. Bull. Amer. Meteor. Soc. 2013;94:169-86. doi:10.1175/BAMS-D-11-00249.1.

30. Cesana G, Kay JE, Chepfer H, English JM, de Boer G. Ubiquitous low-level liquid-containing Arctic clouds: new observations and climate model constraints from CALIPSO-GOCCP. Geophys Res Lett. 2012;39:L20804. doi:10.1029/2012GL053385.

31. Cesana $\mathrm{G}$ et al. Using in situ airborne measurements to evaluate three cloud phase products derived from CALIPSO. J Geophys Res Atmos. 2016;121:5788-808. doi:10.1002/2015JD024334. 
32.• Van Tricht, K., S. Lhermitte, J. T. M Lenaerts, I. V. Gorodetskaya, T. L'Ecuyer, B. Noel, M. R. van den Broeke, D. D. Turner, and N. P. M. van Lipzig, 2016: Clouds enhance Greenland ice sheet meltwater runoff. Nat Commun. 7. doi:10.1038/ncomms10266. This paper quantifies the influence of clouds on Greenland ice sheet melting.

33. Shupe MD, Intrieri J. Cloud radiative forcing of the Arctic surface: the influence of cloud properties, surface albedo, and solar zenith angle. J Clim. 2004;17(3):616-28.

34. Bennartz R et al. July 2012 Greenland melt extent enhanced by low-level liquid clouds. Nature. 2013;496:83-6. doi:10.1038 /nature12002.

35. Miller N, Shupe M, Cox C, Walden V, Turner D, Steffen K. Cloud radiative forcing at Summit, Greenland. J Clim. 2015;28:6267-80. doi:10.1175/JCLI-D-15-0076.1.

36. Kay, J. E. and T. L'Ecuyer (2013), Observational constraints on Arctic Ocean clouds and radiative fluxes during the early 21 st century. J Geophys Res. 118. doi:10.1002/jgrd.50489.

37. Matus, A. V, and T. S. L'Ecuyer, 2016: Assessing the global radiative effects of mixed-phase clouds. submitted to J Geophys Res.

38. Kay JE, L'Ecuyer T, Gettelman A, Stephens G, O'Dell C. The contribution of cloud and radiation anomalies to the 2007 Arctic sea ice extent minimum. Geophys Res Lett. 2008;35:L08503. doi:10.1029/2008GL033451.

39. Kay JE, Gettelman A. Cloud influence on and response to seasonal Arctic sea ice loss. J Geophys Res. 2009. doi:10.1029/2009JD011773.

40. Kay JE, Hillman B, Klein S, Zhang Y, Medeiros B, Gettelman G, Pincus R, Eaton B, Boyle J, Marchand R, Ackerman T. Exposing global cloud biases in the community atmosphere model (CAM) using satellite observations and their corresponding instrument simulators. J Clim. 2012b;25:5190-207. doi:10.1175/JCLI-D-11-00469.1.

41. Pistone K, Eisenman I, Rmanathan V. Observational determination of albedo decrease caused by vanishing Arctic sea ice. Proc Natl Acad Sci U S A. 2014;111(9):3322-6. doi:10.1073/pnas.1318201111.

42. Hartmann D, Ceppi P. Trends in the CERES dataset, 2000-13: the effects of sea ice and jet shifts and comparison to climate models. $\mathrm{J}$ Clim. 2014;27:2444-56. doi:10.1175/JCLI-D-13-00411.1.

43. Palm SP, Strey ST, Spinhirne J, Markus T. Influence of Arctic sea ice extent on polar cloud fraction and vertical structure and implications for regional climate. J Geophys Res. 2010;115:D21209. doi:10.1029/2010JD013900.

44. Wu DL, Lee JN. Arctic low cloud changes as observed by MISR and CALIOP: implication for the enhanced autumnal warming and sea ice loss. J Geophys Res-Atmos. 2012;117:D07107.

45. Sato K, Inoue J, Kodama Y-M, Overland JE. Impact of Arctic seaice retreat on the recent change in cloud-base height during autumn. Geophys Res Lett. 2012;39:L10503. doi:10.1029/2012GL051850.

46. Schweiger AJ, Lindsay RW, Vavrus S, Francis JA. Relationships between Arctic sea ice and clouds during autumn. J Clim. 2008;21: 4799-810. doi:10.1175/2008JCLI2156.1.

47. Soden BJ, Held IM, Colman R, Shell KM, Kiehl JT, Shields CA. Quantifying climate feedbacks using radiative kernels. J Clim. 2008;21:3504-20.

48. Cox CJ, Walden VP, Rowe PM, Shupe MD. Humidity trends imply increased sensitivity to clouds in a warming Arctic. Nat Commun. 2015;6:10117. doi:10.1038/ncomms10117.

49. Taylor KE et al. Estimating shortwave radiative forcing and response in climate models. J Clim. 2007;20:2530-43. doi:10.1175/jcli4143.1.

50. Zelinka MD, Klein SA, Hartmann DL. Computing and partitioning cloud feedbacks using cloud property histograms. Part I: cloud radiative kernels. J Clim. 2012;25:3715-35. doi:10.1175/JCLI-D-11-00248.1.

51. Shell KM, Kiehl JT, Shields CA. Using the radiative kernel technique to calculate climate feedbacks in NCAR's community atmosphere model. J Clim. 2008;21:2269-82. doi:10.1175/2007 JCLI2044.1.
52. DeWeaver ET, Hunke EC, Holland MM. Comment on "On the reliability of simulated Arctic sea ice in global climate models" by I. Eisenmann, N. Untersteiner, and J.S. Wettlaufer. Geophys Res Lett. 2008;35:L04501. doi:10.1029/2007GL031325.

53. Krikken F, Hazeleger W. Arctic energy budget in relation to sea ice variability on monthly-to-annual time scales. J Clim. 2015;28(16): 6335-50. doi:10.1175/JCLI-D-15-0002.1.

54. Kato S, Loeb NG, Rose FG, Doelling DR, Rutan DA, Caldwell TE, et al. Surface irradiances consistent with CERES-derived top-ofatmosphere shortwave and longwave irradiances. J Clim. 2013;26(9):2719-40.

55. Shupe, M. D., D. D. Turner, A. B. Zwink, M. M. Thieman, E. J. Mlawer, and T. R. Shippert, 2015 Deriving Arctic cloud microphysics at Barrow, Alaska: algorithms, results, and radiative closure. B. 54:1675-1689. doi:10.1175/JAMC-D-15-0054.1.

56. O’Dell CW, Wentz FJ, Bennartz R. Cloud liquid water path from satellite-based passive microwave observations: a new climatology over the global oceans. J Clim. 2008;21:1721-39. doi:10.1175 /2007JCLI1958.1.

57. Hurrell J, Holland MM, Gent PR, Ghan S, Kay JE, Kushner P, Lamarque J-F, Large WG, Lawrence D, Lindsay K, Lipscomb WH, Long M, Mahowald N, Marsh D, Neale R, Rasch P, Vavrus S, Vertenstein M, Bader D, Collins WD, Hack JJ, Kiehl J, Marshall S. The community earth system model: a framework for collaborative research. Bull. Amer. Meteor. Soc. 2013. doi:10.1175/BAMS-D12-00121.1.

58. Kay JE, Bourdages L, Chepfer H, Miller N, Morrison A, Yettella V, Eaton B. Evaluating and improving cloud phase in the community atmosphere model version 5 using spaceborne lidar observations. J Geophys Res. 2016;121(8):4162-76. doi:10.1002/2015JD024699.

59. Bitz CM, Holland MM, Hunke E, Moritz RE. Maintenance of the sea-ice edge. J Clim. 2005;18:2903-21.

60. Caldwell PM, Bretherton CS, Zelinka MD, Klein SA, Santer BD, Sanderson BM. Statistical significance of climate sensitivity predictors obtained by data mining. Geophys Res Lett. 2014;41:1803-8. doi:10.1002/2014GL059205.

61. Kay JE et al. The community earth system model (CESM) large ensemble project: a community resource for studying climate change in the presence of internal climate variability. Bull. Amer. Meteor. Soc. 2015. doi:10.1175/BAMS-D-13-00255.1. This paper documents a new large initial condition ensemble that is available publicly and documents climate change in the presence of internal climate variability.

62. Swart NC, Fyfe JC, Hawkins E, Kay JE, Jahn A. Influence of internal variability on Arctic sea-ice trends. Nat Clim Chang. 2015;5:86-9. doi:10.1038/nclimate2483.

63. Chepfer H, Bony S, Winker D, Chiriaco M, Dufresne J-L, Sèze G. Use of CALIPSO lidar observations to evaluate the cloudiness simulated by a climate model. Geophys Res Lett. 2008;35:L15704. doi:10.1029/2008GL034207.

64. Bodas-Salcedo A et al. COSP: satellite simulation software for model assessment. Bull Amer Meteor Soc. 2011;92:1023-43.

65. Cesana G, Chepfer H. Evaluation of the cloud thermodynamic phase in a climate model using CALIPSO-GOCCP. J Geophys Res Atmos. 2013;118:7922-37. doi:10.1002/jgrd.50376.

66. English JM, Kay JE, Gettelman A, Liu X, Wang Y, Zhang Y, Chepfer H. Contributions of clouds, surface albedos, and mixedphase ice nucleation schemes to Arctic radiation biases in CAM5. J Clim. 2014. doi:10.1175/JCLI-D-13-00608.1.

67. Neale, R. B. et al. (2012) Description of the NCAR Community Atmosphere Model (CAM5), technical report NCAR/TN-486+STR, national center for atmospheric research, Boulder, Colorado, $268 \mathrm{pp}$.

68. Chepfer H, Bony S, Winker D, Cesana G, Dufresne JL, Minnis P, Stubenrauch CJ, Zeng S. The GCM-oriented CALIPSO cloud product (CALIPSO-GOCCP. J Geophys Res. 2010;115:D00H16. doi:10.1029/2009JD012251. 
69. Kay JE, Raeder K, Gettelman A, Anderson J. The boundary layer response to recent Arctic sea ice loss and implications for highlatitude climate feedbacks. J Clim. 2011;24:428-47. doi:10.1175 /2010JCLI3651.1.

70. Barton NP, Klein SA, Boyle JS, Zhang YY. Arctic synoptic regimes: comparing domain-wide Arctic cloud observations with CAM4 and CAM5 during similar dynamics. J Geophys Res. 2012;117:D15205. doi:10.1029/2012JD017589.

71. Taylor PC, Kato S, Xu K-M, Cai M. Covariance between Arctic sea ice and clouds within atmospheric state regimes at the satellite footprint level. J Geophys Res Atmos. 2015;120:12656-78. doi:10.1002/2015JD023520.

72. Illingworth AJ et al. The EarthCARE satellite: the next step forward in global measurements of clouds, aerosols, precipitation, and radiation. BAMS. 2015;96(8):1311-32. doi:10.1175/BAMS-D-12-00227.1.

73. de Boer, G., M.D. Ivey, B. Schmid, S. McFarlane, and R. Petty (2016) Unmanned platforms monitor the Arctic atmosphere. EOS. 97. doi:10.1029/2016EO046441. 